\title{
Influence of Temperature and Frequency on Minority Carrier Diffusion Coefficient in a Silicon Solar Cell under Magnetic Field
}

\author{
Seydina Diouf', Mor Ndiaye1, Ndeye Thiam², Youssou Traore1, Mamadou Lamine Ba², Ibrahima \\ Diatta1, Marcel Sitor Diouf1, Oulimata Mballo', Amary Thiam', Ibrahima Ly², Grégoire Sissoko1 \\ ${ }^{1}$ Laboratory of Semiconductors and Solar Energy, Physics Department, Faculty of Science and Technology, \\ University Cheikh Anta Diop, Dakar, Senegal \\ ${ }^{2}$ Electromechanical Department, Polytechnic School of Thiès, Thiès, Senegal \\ Email: gsissoko@yahoo.com
}

How to cite this paper: Diouf, S., Ndiaye, M., Thiam, N., Traore, Y., Ba, M.L., Diatta, I., Diouf, M.S., Mballo, O., Thiam, A., Ly, I. and Sissoko, G. (2019) Influence of Temperature and Frequency on Minority Carrier Diffusion Coefficient in a Silicon Solar Cell under Magnetic Field. Energy and Power Engineering, 11, 355-361. https://doi.org/10.4236/epe.2019.1110023

Received: August 26, 2019

Accepted: October 19, 2019

Published: October 22, 2019

Copyright $\odot 2019$ by author(s) and Scientific Research Publishing Inc. This work is licensed under the Creative Commons Attribution International License (CC BY 4.0).

http://creativecommons.org/licenses/by/4.0/

\section{(c) (i) Open Access}

\begin{abstract}
In this study, the effects of temperature and frequency on minority carrier diffusion coefficient in silicon solar cell under a magnetic field are presented. Using two methods (analytic and graphical), the optimum temperature corresponding to maximum diffusion coefficient is determined versus cyclotronic frequency and magnetic field.
\end{abstract}

\section{Keywords}

Solar Cell, Diffusion Coefficient, Temperature, Magnetic Field, Frequency

\section{Introduction}

Minority carrier diffusion coefficient is a recombination parameter which has a big impact on photovoltaic conversion efficiency. His determination is fundamental for different techniques characterization of solar cells. Many studies have been conducted on the minority carrier diffusion coefficient under the influence of temperature, damage coefficient, irradiation flux and magnetic field in static regime [1] [2] [3] or dynamic frequency regime [4] [5] [6] [7].

In this work, the maximum diffusion coefficient in silicon solar cell is determined according to the optimum temperature for different frequency and magnetic field values.

\section{Study of the Diffusion Coefficient}

The expression of minority carrier diffusion coefficient in solar cell under dynamic frequency regime versus the magnetic field and the temperature is given 
by the following relation [4] [5]:

$D(\omega, B, T)=D(B, T) \times \frac{\left[\left(1+\tau^{2}\left(\omega_{c}(B)^{2}+\omega^{2}\right)\right)\right]+j \omega \tau\left[\tau^{2}\left(\omega_{c}(B)^{2}-\omega^{2}\right)-1\right]}{\left[1+\tau^{2}\left(\omega_{c}(B)^{2}-\omega^{2}\right)\right]^{2}+4 \omega^{2} \tau^{2}}$

With

$$
D(B, T)=\frac{D(T)}{1+[\mu(T) \times B]^{2}}
$$

$D(B, T)$ is the minority carrier diffusion coefficient under influence temperature $T$ and applied magnetic field $B$ [2].

$$
D(T)=\mu(T) \times \frac{K b \times T}{q}
$$

$D(T)$ is the diffusion coefficient versus temperature $T$, in the solar cell without magnetic field [3] [8].

$\mu(T)$ is the minority carriers mobility temperature [9] [10], dependent in the base and expresses as:

$$
\mu(T)=1.43 \times 10^{9} T^{-2.42} \mathrm{~cm}^{2} \cdot \mathrm{V}^{-1} \cdot \mathrm{s}^{-1}
$$

$q$ is the electron elementary charge

$K b$ is Boltzmann's constant given as $K b=1.38 \times 10^{-23} \mathrm{~m}^{2} \cdot \mathrm{kg} \cdot \mathrm{s}^{-2} \cdot \mathrm{K}^{-1}$

$$
\omega_{c}(B)=\frac{q B}{m_{e}}
$$

$\omega_{c}(B)$ is cyclotronic frequency of electron [11] [12].

Figure 1 represents the minority carrier diffusion coefficient according to frequency for different values magnetic field at the temperature $T=300 \mathrm{~K}$.

The maximum minority carrier diffusion coefficient in solar cell is obtained when the modulation frequency is equal to cyclotronic frequency. Thus, the

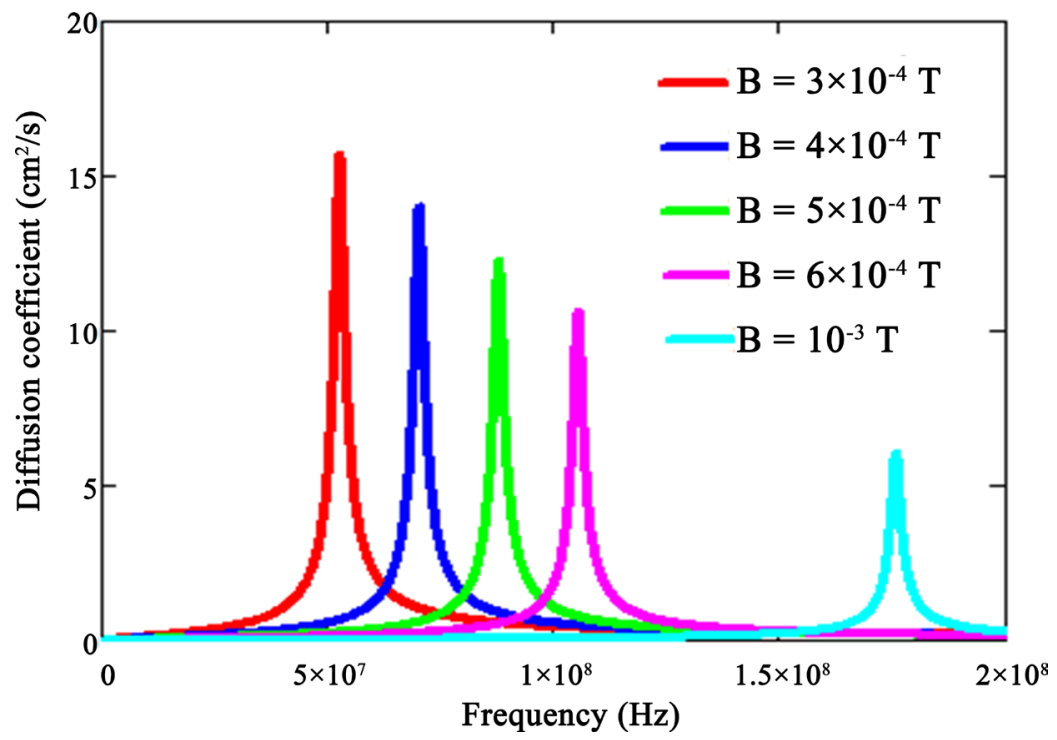

Figure 1. Diffusion coefficient versus frequency for different values magnetic field at the temperature $T=300 \mathrm{~K}$. 
curves of this figure make it possible to obtain the cyclotronic frequency for different values magnetic field.

For the rest of the work, Table 1 will allow us to set the value magnetic field for each cyclotronic frequency.

\subsection{Determination of the Optimal Temperature by Graphic Method}

Figure 2 represents the minority carrier diffusion coefficient according to temperature for different pairs' values cyclotronic frequency and the magnetic field.

The minority carrier diffusion coefficient increases with temperature up to a maximum value $D n_{\max }(\omega, B)$ corresponding to temperature called optimum temperature $T_{o p t}(\omega, B)$ for a given cyclotronic frequency and magnetic field. Indeed, when the temperature is lower than the optimal temperature $T_{\text {opt }}(\omega, B)$. Indeed, when the temperature is lower than the optimal temperature $T_{o p t}(\omega, B)$, the number phonons [13] [14] of high energy varies as an exponential form, according to Boltzmann's law. The Umklapp processes [13] [14] no longer limit thermal conductivity, which varies in $\mathrm{T}^{3}$. There is not too much thermal agitation hence the increase in the minority carrier diffusion coefficient.

On the other hand for temperatures higher than $T_{o p t}(\omega, B)$ the minority carrier diffusion coefficient decreases. Phonons are excited for temperatures above the optimum temperature. There is thermal agitation hence the decrease in minority

Table 1. Cyclotronic frequency for different magnetic field values.

\begin{tabular}{cccccc}
\hline$B($ Tesla $)$ & $3 \times 10^{-4}$ & $4 \times 10^{-4}$ & $5 \times 10^{-4}$ & $6 \times 10^{-4}$ & $10^{-3}$ \\
$\omega_{c}(B) \mathrm{rad} / \mathrm{s}$ & $5.30 \times 10^{7}$ & $7.03 \times 10^{7}$ & $8.84 \times 10^{7}$ & $1.06 \times 10^{8}$ & $1.76 \times 10^{8}$ \\
\hline
\end{tabular}

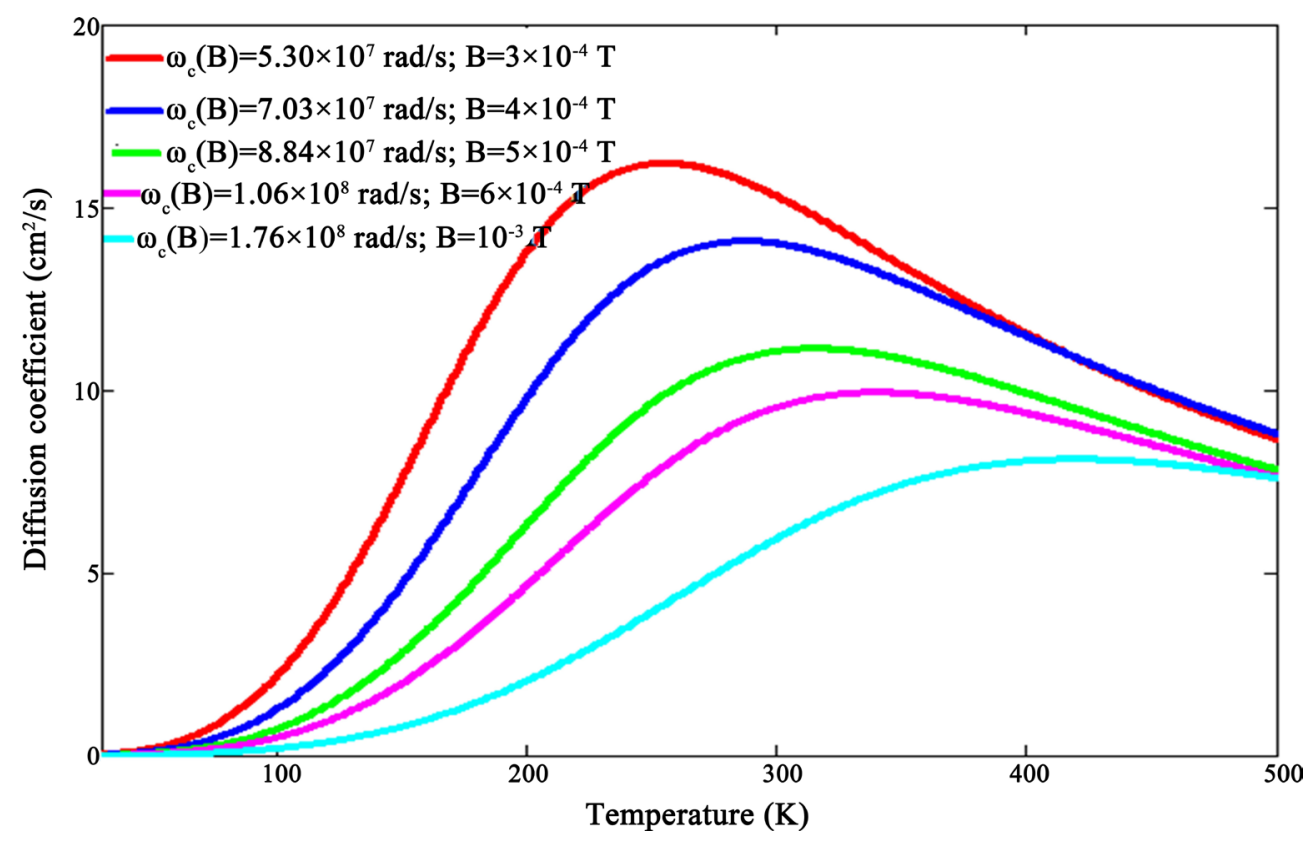

Figure 2. Diffusion coefficient versus temperature for different pairs values cyclotronic frequency and the magnetic field. 
carrier diffusion coefficient.

From the curves in Figure 3, the values of optimum temperature and maximum diffusion coefficient for each pair cyclotronic frequency and magnetic field are determined and presented in the following Table 2.

Table 3 allowed to represent the following figures.

The curve obtained can be assimilated to an affine function of equation:

$$
\begin{gathered}
\ln D_{\text {max }}(\omega, B)=a \ln T_{o p t}(\omega, B)+b \\
D_{\text {max }}(\omega, B)=\mathrm{e}^{b} \times\left[T_{o p t}(\omega, B)\right]^{a}
\end{gathered}
$$

The constants $\mathrm{a}$ and $\mathrm{b}$ are determined from the curve, the following equations is obtained:

$$
\begin{gathered}
2.645=5.67 a+b \\
2.296=5.838 a+b \\
D_{\max }(\omega, B)=1.717 \times 10^{6}\left[T_{\text {opt }}(\omega, B)\right]^{-2.065}
\end{gathered}
$$

These results obtained by the graphical method can be verified by an analytical method.

\subsection{Determination of Optimal Temperature by Analytical Method}

The minority carrier diffusion coefficient curve versus temperature admits a

Table 2. Values optimum temperature and maximum diffusion coefficient for each pair cyclotronic frequency and magnetic field.

\begin{tabular}{cccccc}
\hline$\omega_{c}(B) \mathrm{rad} / \mathrm{s}$ & $5.30 \times 10^{7}$ & $7.03 \times 10^{7}$ & $8.84 \times 10^{7}$ & $1.06 \times 10^{8}$ & $1.76 \times 10^{8}$ \\
$B($ Tesla $)$ & $3 \times 10^{-4}$ & $4 \times 10^{-4}$ & $5 \times 10^{-4}$ & $6 \times 10^{-4}$ & $10^{-3}$ \\
$D\left(\mathrm{~cm}^{2} / \mathrm{s}\right)$ & 16.212 & 14.079 & 11.138 & 9.934 & 8.108 \\
$T_{\text {opt }}(\mathrm{K})$ & 257 & 290 & 318 & 343 & 424 \\
\hline
\end{tabular}

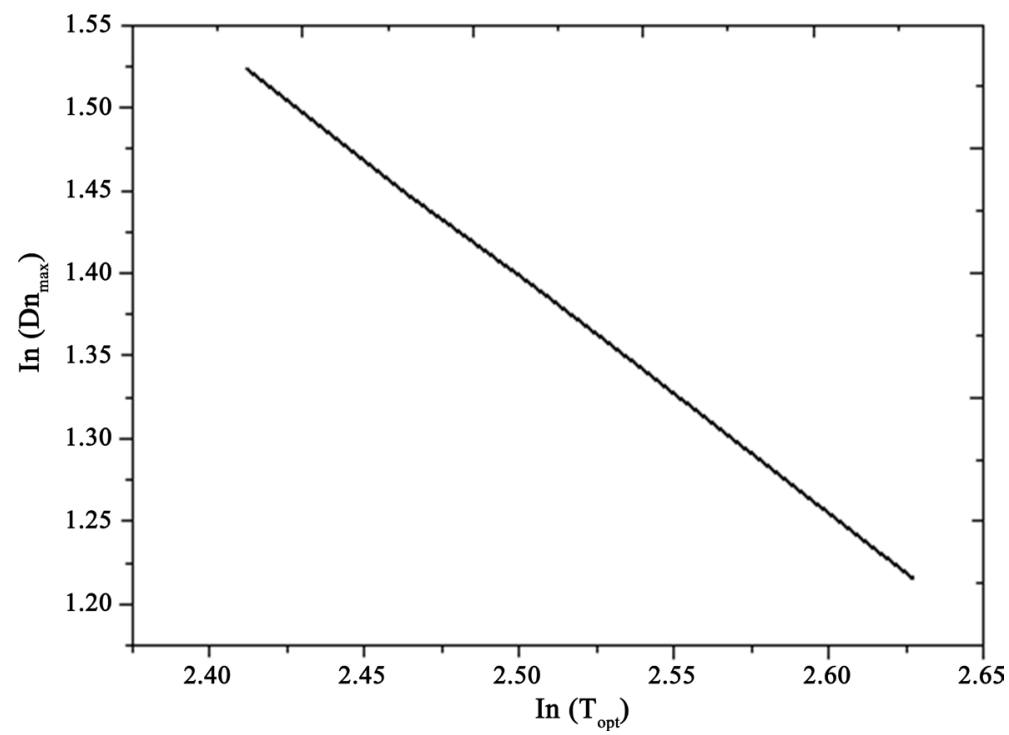

Figure 3. Log-log maximum diffusion coefficient versus optimum temperature. 
maximum corresponding to optimum temperature $T_{o p t}(\omega, B)$. This optimum temperature can be obtained by solving the following equation:

$$
\frac{\mathrm{d} D(\omega, B, T)}{\mathrm{d} T}=0
$$

Finally we get:

$$
\begin{aligned}
& T_{\text {opt }}(\omega, B) \\
& =\sqrt[-1.84]{\frac{2.272 \times 10^{-19}}{1.184 \times B^{2}} \frac{\left[1+\tau^{2}\left(\omega_{c}(B)^{2}+\omega\right)\right]+j \omega \tau\left[\tau^{2}\left(\omega_{c}(B)^{2}-\omega^{2}\right)-1\right]}{j \omega \tau^{3} \omega_{c}(B)^{2}-j \omega^{3} \tau^{3}-j \omega \tau+\left[1+\tau^{2}\left(\omega_{c}(B)^{2}+\omega^{2}\right)\right]}}
\end{aligned}
$$

The relation allows deducing the values of optimum temperature $T_{\text {opt }}(\omega, B)$ for different values cyclotronic frequency and magnetic field.

Log-log maximum diffusion coefficient versus optimum temperature is presented by Figure 4.

For a comparative study of two methods, we represent in Figure 5, on log-log scale, profiles of amplitude diffusion coefficient versus optimum temperature.

Note that two curves are almost confused. Thus, the relation obtained will make it possible to justify the choice the values temperature, magnetic field and

Table 3. Values optimum temperature and maximum diffusion coefficient for each pair cyclotronic frequency and magnetic field.

\begin{tabular}{cccccc}
\hline$\omega_{c}(B) \mathrm{rad} / \mathrm{s}$ & $5.30 \times 10^{7}$ & $7.03 \times 10^{7}$ & $8.84 \times 10^{7}$ & $1.06 \times 10^{8}$ & $1.76 \times 10^{8}$ \\
$B($ Tesla $)$ & $3.03 \times 10^{-4}$ & $4.004 \times 10^{-4}$ & $5.031 \times 10^{-4}$ & $6.031 \times 10^{-4}$ & $1.001 \times 10^{-3}$ \\
$T_{\text {opt }}(\mathrm{K})$ & 257.871 & 290.422 & 318.475 & 343.396 & 424.099 \\
$D\left(\mathrm{~cm}^{2} / \mathrm{s}\right)$ & 16.209 & 14.078 & 11.137 & 9.934 & 8.108 \\
\hline
\end{tabular}

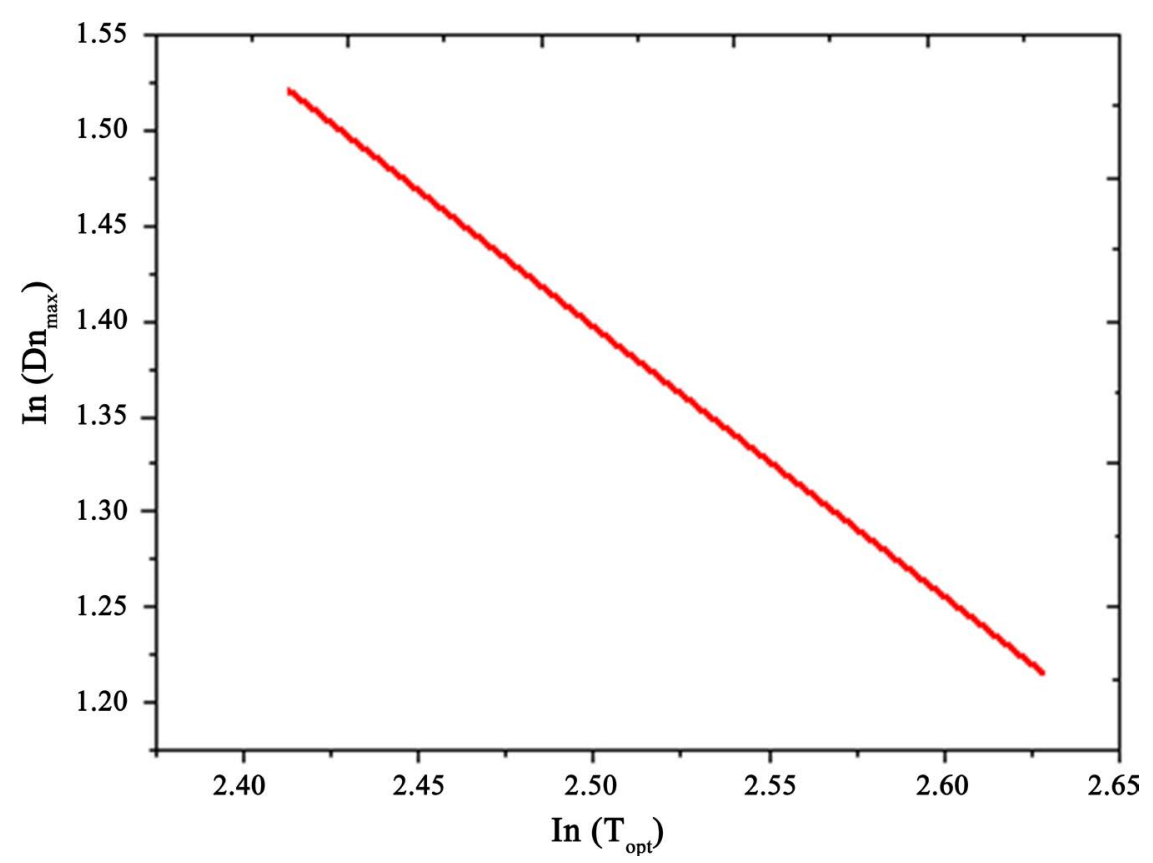

Figure 4. Log-log maximum diffusion coefficient versus optimum temperature. 


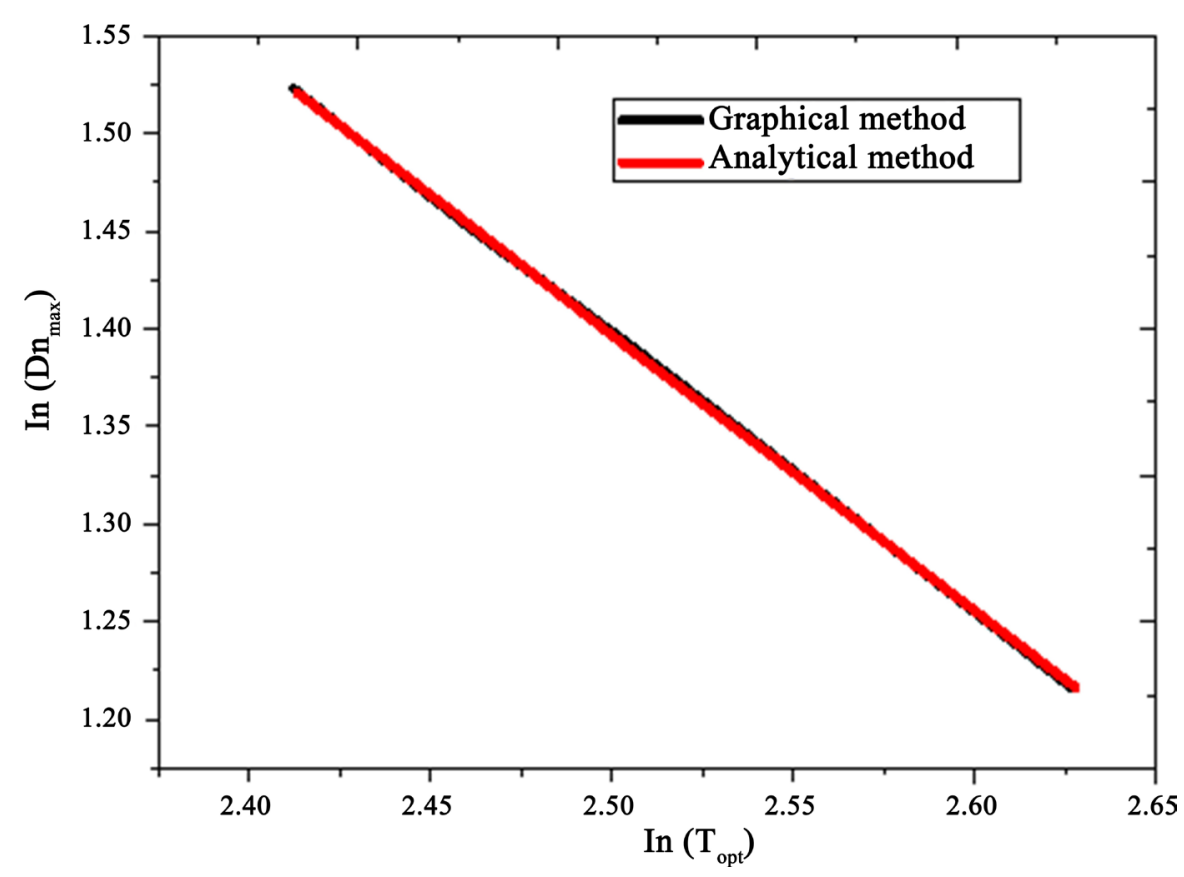

Figure 5. Log-log maximum diffusion coefficient versus optimum temperature for both methods.

frequency in the study of different parameters a silicon solar cell.

\section{Conclusion}

The study of minority carrier diffusion coefficient in silicon solar cell has shown that the choice of parameter values such as temperature, magnetic field and frequency must obey certain conditions for a good performance of solar cells. Thus, the optimum temperature $T_{o p t}(\omega, B)$ for a maximum minority carrier diffusion coefficient is obtained using the pairs of cyclotronic frequency and magnetic field values presented in Table 2 and Table 3.

\section{Conflicts of Interest}

The author declares no conflicts of interest regarding the publication of this paper.

\section{References}

[1] Ngom, M.I., Zouma, B., Zoungrana, M., Thiame, M., Bako, Z.N., Camara, A.G. and Sissoko, G. (2012) Theoretical Study of a Parallel Vertical Multijunction Silicon Cell under Multispectral Illumination: Influence of External Magnetic Field on the Electrical Parameters. International Journal of Advanced Technology \& Engineering Research, 2, 101-109.

[2] Mane, R., Ly, I., Wade, M., Diatta, I., Diouf, M.S., Traore, Y., Ndiaye, M., Tamba, S. and Sissoko, G. (2017) Minority Carrier Diffusion Coefficient D (B, T): Study in Temperature on a Silicon Solar Cell under Magnetic Field. Energy and Power Engineering, 9, 1-10. https://doi.org/10.4236/epe.2017.91001

[3] Diatta, I., Diagne, I., Sarr, C., Faye, K., Ndiaye, M. and Sissoko, G. (2015) Silicon Solar Cell Capacitance: Influence of Both Temperature and Wavelength. Interna- 
tional Journal of Computer Science, 3, 1-8.

[4] Diao, A., Thiam, N., Zoungrana, M., Sahin, G., Ndiaye, M. and Sissoko, G. (2014) Diffusion Coefficient in Silicon Solar Cell with Applied Magnetic Field and under Frequency: Electric Equivalent Circuits. World Journal of Condensed Matter Physics, 4, 84-92. https://doi.org/10.4236/wjcmp.2014.42013

[5] Dieng, A., Zerbo, I., Wade, M., Maiga, A.S. and Sissoko, G. (2011) Three-Dimensional Study of a Polycrystalline Silicon Solar Cell: The Influence of the Applied Magnetic Field on the Electrical Parameters. Semiconductor Science and Technology, 26, Article ID: 095023.

https://doi.org/10.1088/0268-1242/26/9/095023

[6] Ndiaye, E.H., Sahin, G., Dieng, M., Thiam, A., Ly Diallo, H., Ndiaye, M. and Sissoko, G. (2015) Study of the Intrinsic Recombination Velocity at the Junction of Silicon Solar under Frequency Modulation and Irradiation. Journal of Applied Mathematics and Physics, 3, 1522-1535. https://doi.org/10.4236/jamp.2015.311177

[7] Tall, I., Seibou, B., El Moujtaba, M.A.O., Diao, A., Wade, M. and Sisoko, G. (2015) Diffusion Coefficient Modeling of a Silicon Solar Cell under Irradiation Effect in Frequency: Electric Equivalent Circuit. International Journal of Engineering Trends and Technology, 19, 56-61. https://doi.org/10.14445/22315381/IJETT-V19P211

[8] Diatta, I., Ly, I., Wade, M., Diouf, M.S., Mbodji, S. and Sissoko, G. (2016) Temperature Effect on Capacitance of a Silicon Solar Cell under Constant White Biased Light. World Journal of Condensed Matter Physics, 6, 261-268. https://doi.org/10.4236/wjcmp.2016.63024

[9] Kunst, M. and Sanders, A. (1992) Transport of Excess Carriers in Silicon Wafers. Semiconductor Science and Technology, 7, 51-59. https://doi.org/10.1088/0268-1242/7/1/009

[10] Schroder, D.K., Whitfield, J.D. and Varker, C.J. (1984) Recombination Lifetime Using the Pulsed Mos Capacitor. Transactions on Electron Devices, 31, 462-467. https://doi.org/10.1109/T-ED.1984.21551

[11] Kittel, C. (1972) Introduction à la Physique de l'état Solide. 284-285.

[12] Kittel, C. (1998) Physique de l'état Solide. 7th Edition, 192.

[13] Gerl, M. and Issi, J.P. (1997) Physique des matériaux. Volume 8, 57.

[14] Kittel, C. (1998) Physique de l'état solide. 7th Edition, 123-126. 